\title{
Survivorship support in head and neck cancer: American Head and Neck Society survey
}

\author{
David M. Cognetti MD ${ }^{1}$ (1) | Victoria M. Villaflor $\mathrm{MD}^{2}$ | \\ Carole Fakhry MD, MPH $^{3} \quad$ Matthew C. Miller MD $^{4}$ | Kelly M. Malloy MD
}

\author{
${ }^{1}$ Department of Otolaryngology, Sydney \\ Kimmel Medical College at Thomas \\ Jefferson University, Philadelphia, \\ Pennsylvania \\ ${ }^{2}$ Department of Medical Oncology, Robert \\ H Lurie Comprehensive Cancer Center of \\ Northwestern University, Chicago, Illinois \\ ${ }^{3}$ Department of Otolaryngology, Johns \\ Hopkins University School of Medicine, \\ Baltimore, Maryland \\ ${ }^{4}$ Department of Otolaryngology, \\ University of Rochester School of \\ Medicine, Rochester, New York \\ ${ }^{5}$ Department of Otolaryngology, \\ University of Michigan Medical School, \\ Ann Arbor, Michigan \\ Correspondence \\ David M. Cognetti, Sydney Kimmel \\ Cancer Center at Thomas Jefferson \\ University, Philadelphia, PA. \\ Email: david.cognetti@jefferson.edu
}

\begin{abstract}
Background: The value of supporting cancer survivors beyond formal treatment has become increasingly recognized among clinicians who care for patients with head and neck cancer.

Methods: A survey was developed by the American Head and Neck Society (AHNS) Survivorship Committee and distributed to members of the AHNS electronically.

Results: The survey was distributed to 1403 AHNS members, with 202 responses (14.4\%). Among survivorship topics, respondents were most likely to address detection of recurrence/second primary malignancies (97.5\%), dysphagia (93.1\%), and thyroid function (90.1\%) with their patients; they were least likely to address sleep disturbance/apnea (27.7\%) and body and self-image issues $(29.7 \%$.) Less than half provide patients with a written treatment summary (43.1\%) or follow-up care plan (36.9\%).
\end{abstract}

Conclusions: These results highlight the need for improved survivorship care planning and offer an opportunity for the development of educational and survivorship research in head and neck cancer care.

\section{K E Y W O R D S}

head and neck cancer, surveillance, survivorship, treatment plan

\section{1 | INTRODUCTION}

Cancer can have a devastating impact on its victims and their families. In addition to the physical toll, cancer and its treatment often result in psychological, social, and financial burdens. This is especially true of malignancies of the head and neck, given the aesthetic and functional importance of this area. As such, it is appropriate that as the treatment of head and neck cancer has shifted from radical ablation to curative treatment that also focuses on the preservation and restoration of function, the importance of quality of life after therapy has become increasingly recognized. ${ }^{1}$ In 2005 , the Institute of
Medicine (IOM) published the landmark report From Cancer Patient to Cancer Survivor: Lost in Transition that highlighted the increasing number of cancer survivors who were understudied by the research community and often lost to follow-up by care providers. ${ }^{2}$ In this report, guidelines for strategies to improve the quality of life of cancer survivors are provided. A notable recommendation was the provision of a written survivorship care plan. Until recently, there were no standardized care plans or treatment summaries for head and neck cancer survivors although the Commission on Cancer ( $\mathrm{CoC}$ ) of the American College of Surgeons has adopted this as a quality benchmark for cancer programs. The American Head 
and Neck Society (AHNS) recently published a primer on survivorship in head and neck cancer that includes a head and neck cancer treatment summary template. ${ }^{3}$ Additionally, the American Cancer Society (ACS) also recently published a consensus statement outlining the potential issues experienced by head and neck cancer survivors. ${ }^{4}$ Therefore, given the recent interest in head and neck cancer survivorship, this study was designed to assess the current knowledge and attitudes pertaining to survivorship among members of the AHNS.

\section{2 | METHODS}

The Survivorship Committee of the AHNS sponsored this project. Members of the committee developed a 16-question survey. The survey covered respondent demographics, practice patterns, and familiarity with current recommendations related to survivorship in head and neck cancer. The survey was electronically distributed to 1403 members of the AHNS. Data were collected anonymously via an online SurveyMonkey poll. Descriptive statistics were used to summarize variables of interest. Subgroup analysis based on demographic responses to fellowship completion, practice type, and years in practice was performed using Fisher's exact test.

T A B L E 1 Information on respondents

\begin{tabular}{lc}
$\begin{array}{ll}\text { Characteristic } & \text { No. of } \\
\text { respondents (\%) }\end{array}$ \\
$\begin{array}{l}\text { How long ago did } \\
\text { you complete training? }\end{array}$ \\
$\quad$ <5 years & $40(19.8 \%)$ \\
$5-14$ years & $63(31.2 \%)$ \\
15-25 years & $46(22.8 \%)$ \\
$>25$ years & $53(26.2 \%)$ \\
What is your primary practice? & \\
Academic & $157(78.1 \%)$ \\
Private practice & $28(13.9 \%)$ \\
Government & $10(5.0 \%)$ \\
Managed Care & $6(3.0 \%)$ \\
What percentage of your & \\
practice involves head and & \\
neck cancer care? & \\
$<25 \%$ & $18(8.9 \%)$ \\
$25-50 \%$ & $20(9.9 \%)$ \\
$50-75 \%$ & $38(18.8 \%$ \\
$>75 \%$ & $126(62.4 \%)$ \\
\hline
\end{tabular}

\section{3 | RESULTS}

\section{Respondent characteristics}

Responses were received from 202 of the 1403 recipients for a response rate of $14.4 \%$. The characteristics of the respondents are summarized in Table 1 . The vast majority of respondents were otolaryngologists $(80.7 \%)$ and completed fellowship training (84.1\%).

\section{Current practice}

Respondents were questioned regarding their familiarity with the ACS Care Guideline. This guideline details key recommendations for assessment and management of long-term issues common to survivors of head and neck cancer. Only 55.9\% of respondents expressed familiarity with the ACS care guideline. However, when asked whether specific survivorship issues outlined by the

TABLE 2 Assessed conditions

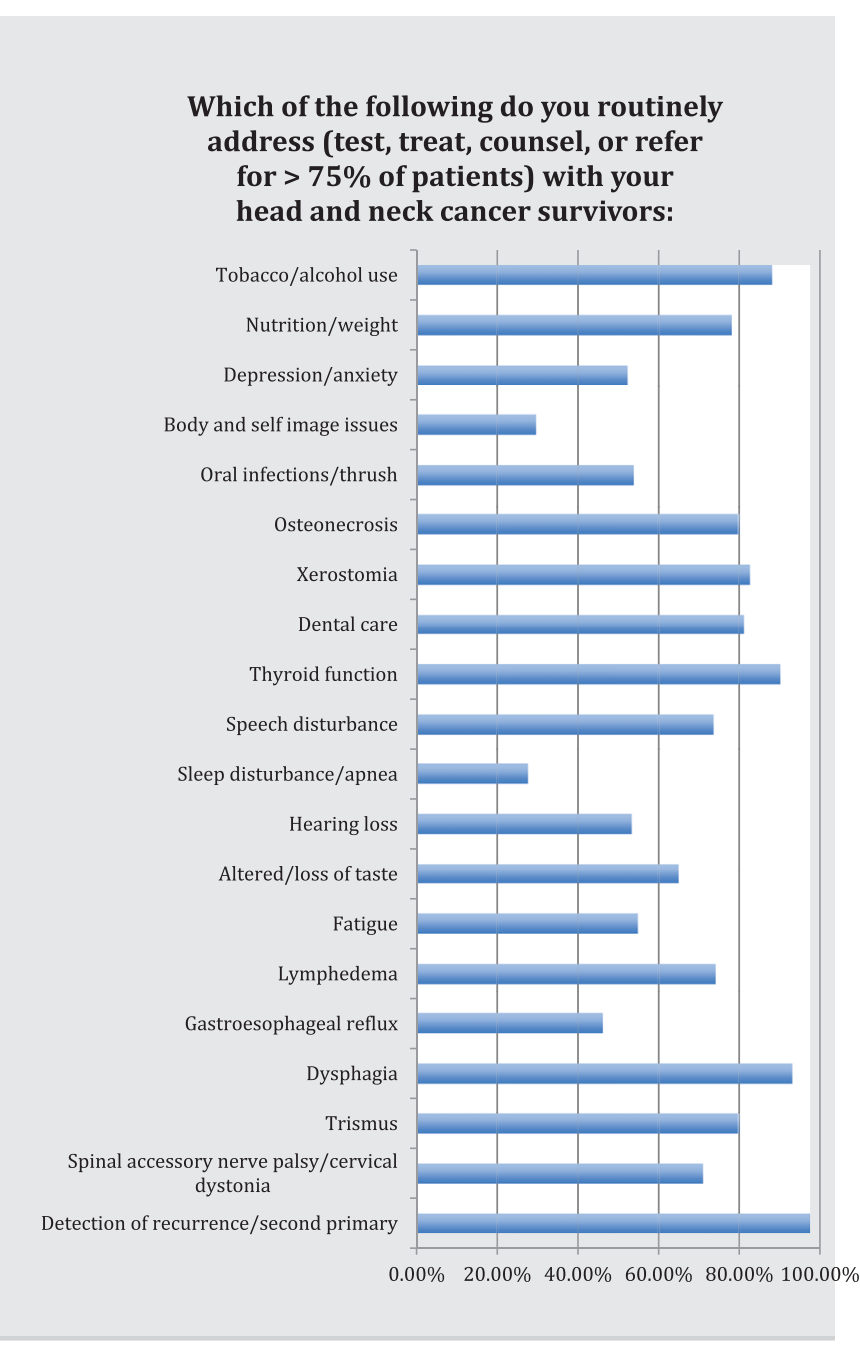


T A B L E 3 State of survivorship

\begin{tabular}{|c|c|c|c|}
\hline \multirow[b]{2}{*}{ Question } & \multicolumn{3}{|c|}{ No. of respondents (\%) } \\
\hline & Yes & No & $\begin{array}{l}\text { I do not know/in } \\
\text { development }\end{array}$ \\
\hline $\begin{array}{l}\text { Are you familiar with the American Cancer Society } \\
\text { Survivorship Care Guideline? }\end{array}$ & $113(55.9 \%)$ & $89(44.1 \%)$ & 0 \\
\hline $\begin{array}{l}\text { Does your institute have a dedicated head and neck } \\
\text { survivorship clinic? }\end{array}$ & $51(25.2 \%)$ & $127(62.9 \%)$ & $24(11.9 \%)$ \\
\hline $\begin{array}{l}\text { Do your patients receive a written treatment } \\
\text { summary at the completion of therapy (from you } \\
\text { or any member of treatment team)? }\end{array}$ & $87(43.1 \%)$ & $92(45.5 \%)$ & $23(11.4 \%)$ \\
\hline $\begin{array}{l}\text { Do you patients receive a written follow-up care } \\
\text { plan at completion of therapy (from you or any } \\
\text { member of the treatment team)? }\end{array}$ & $73(36.9 \%)$ & $99(50.0 \%)$ & $26(13.1 \%)$ \\
\hline
\end{tabular}

guideline were addressed by respondents, a higher proportion reported routinely addressing them in practice for 13 of the 20 assessed issues (Table 2). Of the survivorship issues evaluated, respondents were most likely to address detection of recurrence/second primary malignancy (97.5\%), dysphagia (93.1\%), and thyroid function (90.1\%) while they were least likely to address sleep disturbance/ apnea (27.7\%) and body and self-image issues (29.7\%.)

Respondents reported maintaining close surveillance of patients early after completion of cancer treatment. The most frequent intervals for follow-up appointments during the first year for patients who had completed their cancer treatment were every 2 months (40.8\%) and every 3 months (41.3\%). Only three respondents (1.5\%) reported seeing patients at 6-month intervals during the first year with none reporting that they did not follow the patients. The remaining $16.4 \%$ saw patients at 1-month intervals for the first 12 months. Similarly, the majority of respondents provide active involvement in long-term surveillance with $62.9 \%$ reporting that they never discharge survivors from their practice and only two respondents (1.0\%) reporting that they discharge survivors prior to 5 years.

Consistent with the patterns of surveillance, $77.7 \%$ of respondents reported the head and neck surgeon as primarily responsible for survivorship care of head and neck cancer survivors. A survivorship nurse or nurse practitioner was reported as primarily responsible by $12.4 \%$ of respondents. Primary care physician (PCP), general otolaryngologist, radiation oncologist, and medical oncologist were reported as primarily responsible by less than $3 \%$ of respondents each. Respondents who completed fellowship training (vs those who did not) reported a higher percentage of head and neck surgeons $(80.5 \%$ vs $62.5 \%)$ and survivorship nurse/nurse practitioner (13\% vs $9.4 \%$ ) as primarily responsible for head and neck survivorship care at their institution $(P=.005$.) Respondents in Academic practice (vs those in private practice) reported a higher percentage of survivorship nurse/nurse practitioner $(15.3 \%$ vs $0 \%)$ as primarily responsible $(P=.013$. $)$ Years in practice did not produce a statistically significant difference in who was primarily responsible for head and neck survivorship care.

Further questions directed at the current state of survivorship in head and neck cancer are seen in Table 3. Despite a majority of respondents reporting familiarity with the ACS Survivorship Care Guideline, a minority of them reported that their patients receive written treatment summaries and written follow-up care plans. These practices were not statistically different based on fellowship completion, practice setting, or years in practice. Only $25.2 \%$ reported that a dedicated head and neck survivorship clinic exists at their institution. An additional $11.9 \%$ reported that a survivorship clinic was in development at their institution. A dedicated head and neck survivorship clinic was much more likely to be present or in development in the academic setting vs private practice (43.3\% vs $10.3 \%, P=<.001$.) Finally, when asked who should primarily manage long-term and late treatment effects for head and neck patients with cancer, $48.0 \%$ of respondents felt it should be the head and neck surgeon and $40.4 \%$ felt it should a survivorship nurse/nurse practitioner. The percentage of respondents who felt it should be the radiation oncologist was $5.6 \%$ while the percentage selecting PCP, general otolaryngologist, or medical oncologist were less than $2.5 \%$ each. These responses were not statistically different based on fellowship completion, practice type, or years in practice.

\section{4 | DISCUSSION}

The recent increase in incidence of oropharynx cancers and improved overall survival has led to a significant rise in survivors both in the United States and abroad. ${ }^{5,6}$ The 
ACS Survivorship Care Guideline and associated initiatives acknowledge the decline in quality of life that occurs for head and neck patients with cancer both before and after treatment and highlights the need for attention to the sequelae of head and neck cancer diagnosis and treatment well beyond the acute treatment phase. ${ }^{7}$

Our survey indicates that the impact of the IOM's report and the ACS Survivorship Care Guideline among primarily head and neck surgical oncologists has not been fully realized. Just over half of respondents reported familiarity with the Survivorship Care Guideline. Despite treatment summaries and survivorship care plans being a $\mathrm{CoC}$ quality standard, only $43 \%$ and $37 \%$ of respondents report that their survivors receive written treatment summaries and follow-up care plans, respectfully. This is consistent with a recent study of oral/oropharyngeal cancer survivors in which only $35 \%$ of those who were surveyed between 2 and 5 years after their diagnosis had received a written treatment summary. ${ }^{8}$ This may reflect challenges with implementation of a written process. In December of 2017, the CoC decreased the minimum required percentage of delivered survivorship care plans to eligible patients for accredited programs from $75 \%$ to $50 \%$ for 2018 , an indication of the state of penetrance of this initiative.

While the percentage of survivors who reported receiving a written treatment summary in the above study of oral/oropharyngeal cancer survivors was low, 96\% reported that their physician informed them about the need to follow up. ${ }^{8}$ In our survey, while the proportion of respondents who are providing written treatment summaries and survivorship care plans is low, the proportion of respondents who are addressing many of the survivorship issues is high. The detection of recurrence/second primary, dysphagia, thyroid function, and tobacco/alcohol use were of primary interest to the respondents. However, few providers assessed for sleep disturbance/apnea, body and self-image issues, gastroesophageal reflux, and depression/anxiety. Tobacco and alcohol use are established risk factors for recurrence of head and neck cancer, and dysphagia and thyroid dysfunction are common and wellrecognized sequelae of head and neck cancer treatments. Therefore, it appears that the most commonly considered survivorship needs by head and neck surgical oncology providers are the well-established morbidities of head and neck cancer and therapy. However, the unmet needs most frequently mentioned by patients are psychological in nature. ${ }^{9}$ A study of long-term caregivers of patients with head and neck cancer also found greatest levels of unmet needs for partners of patients to occur in the emotional and health service domains. ${ }^{10}$ Head and neck patients with cancer are at high risk for emotional and financial distress, and in our survey depression/anxiety and the associated body and self-image issues are less commonly addressed by respondents. The incidence of depression in patients with $\mathrm{HNC}$ is as high as $40 \% .{ }^{11}$ Unemployment more than doubles after treatment for head and neck cancer, with unemployment linked to decreased functional and social well-being scores and increased depression scores. ${ }^{12}$ Furthermore, the suicide rate among patients with head and neck cancer is three times that of the United States general population, representing the highest suicide rate among all cancer types. ${ }^{13,14}$ Randomized controlled data exist that demonstrate the development of depression can be prophylactically reduced in patients undergoing treatment for head and neck cancer, ${ }^{15}$ and an important step in the treatment of any problem is recognizing it. Therefore, our results suggest need for increased attention to psychological and less common morbidities that impact survivors.

The results of our survey reveal that head and neck surgeons are actively involved in the surveillance of their patients. The reported frequencies of patient visits in the first year after completion of treatment are in line with the recommendations by the National Comprehensive Cancer Network guidelines, ${ }^{11,16}$ and the vast majority of respondents continue to follow their patients for at least 5 years. The most frequently addressed topic in our survey was detection of recurrence/second primary cancer. This corresponds with patient reported understanding in a previous survey in which $76 \%$ of patients expressed that the most important reason for follow-up care is to check for recurrence. ${ }^{8}$ Interestingly, only $1 \%$ of those patients felt that treatment for any symptom or side effect of cancer therapy is the most important reason for follow-up care. However, the yield of surveillance visits in detection of asymptomatic recurrence is low and the impact on survival is questionable, thus leading some to suggest that follow-up visits should focus on other survivorship issues. ${ }^{17,18}$ Furthermore, there is evidence to suggest that the survivorship needs of patients are not adequately being addressed outside of the head and neck specialist's clinic. Although the ACS Survivorship Care Guideline is directed at PCPs, in a recent survey of PCPs, only $32 \%$ felt confident they could manage late/long term side effects of head and neck cancer treatment and only $29 \%$ felt confident they could provide appropriate cancer screening. ${ }^{19}$ Only 3\% of respondents in our survey report that the PCP is primarily responsible for survivorship care in their patients with cancer and only $1.5 \%$ of respondents felt the PCP should be primarily responsible for managing long-term and late treatment effects. Furthermore, the written treatment summaries and survivorship care plans may not achieve their goal of educating patients and their PCPs. A survey of patients and their physicians between 3 and 4 years after receipt of the survivorship care plan revealed that only $10 \%$ of patients and $34 \%$ of their 
community physicians or dentists were able to locate or recall receiving the survivorship care plan, and $90 \%$ of patients were unsure of the value of care plans. ${ }^{20}$

It may be that utilization of written care plans and the PCP is not the optimal way to address survivorship for patients treated for head and neck cancer. In our survey, $12.4 \%$ of respondents report that a survivorship nurse/ nurse practitioner is currently responsible for survivorship care while $40.4 \%$ of respondents feel that a survivorship nurse/nurse practitioner should be primarily responsible for managing long-term and late treatment effects. The discordance of these two numbers likely reflect acknowledgement of a role for nurse practitioner led survivorship clinics by respondents of the survey. Interestingly, there was a higher percentage of survivorship nurse/nurse practitioners (15.3\% vs $0 \%)$ currently primarily responsible for survivorship care reported in the academic setting vs private practice, but no statistical difference for the answer of who should be primarily responsible between the two settings. This suggests that while academic centers are further along in the establishment of survivorship clinics (as confirmed by the percentage of academic setting vs private practice [43.4\% vs $10.3 \%$ ] who have survivorship clinics active or in development), both settings see a value.

Surgeons may be more apt to reassign their role in follow up if the yield of asymptomatic cancer surveillance is seen as low and the survivorship needs are seen as high and/or better addressed by another. This may increasingly be the case due to HPV-related head and neck cancer. Patients with HPV-related head and neck cancer are on average younger. They also have higher cure rates and likely have lower second primary cancer rates. ${ }^{21}$ These factors would contribute to lower yield of cancer surveillance and longer survivorship periods. The optimal structure for coordination of cancer surveillance and survivorship care between the head and neck surgeon and survivorship nurse practitioner and other care providers warrants further investigation.

We acknowledge the limitations of a survey study, including recall bias. Additionally, it is recognized that the vast majority of members of the AHNS and the respondents to this survey are otolaryngology trained head and neck surgeons, which biases the responses to that perspective.

\section{5 | CONCLUSION}

Responding members of the AHNS are actively involved in the follow-up care of their patients with head and neck cancer. However, familiarity with the ACS Survivorship Care Guideline is low and respondents are not meeting the current $\mathrm{CoC}$ accreditation minimum for provision of written treatment summaries and survivorship care plans. While $40 \%$ of respondents report that a survivorship nurse/nurse practitioner should manage the longterm and late treatment effects for head and neck patients with cancer, only $25 \%$ report that a survivorship clinic currently exists at their institution. The optimal structure to address the unique and unmet survivorship needs of patients following the treatment of head and neck cancer warrants further investigation.

\section{ACKNOWLEDGMENT}

We would like to thank Tingting Zhan, PhD and the Biostatistics Share Resource of the Sidney Kimmel Cancer Center of Thomas Jefferson University' for statistical support of this project.

\section{ORCID}

\section{David M. Cognetti (1) https://orcid.org/0000-0001-7039-}

3055

\section{REFERENCES}

1. Cognetti DM, Weber RS, Lai SY. Head and neck cancer: an evolving treatment paradigm. Cancer. 2008;113(7 Suppl):19111932. https://doi.org/10.1002/cncr.23654.

2. From Cancer Patient to Cancer Survivor. Washington, D.C.: National Academies Press; 2005:1-535. doi:https://doi.org/10. 17226/11468.

3. Miller MC, Shuman AG, for the American Head and Neck Society's Committee on Survivorship. Survivorship in head and neck cancer. JAMA Otolaryngol Head Neck Surg. 2016;142:1-7. https://doi.org/10.1001/jamaoto.2016.1615.

4. Cohen EEW, LaMonte SJ, Erb NL, et al. American Cancer Society Head and Neck Cancer Survivorship Care Guideline. CA Cancer J Clin. 2016;66(3):203-239. https://doi.org/10.3322/ caac.21343.

5. Fakhry C, Andersen KK, Eisele DW, Gillison ML. Oropharyngeal cancer survivorship in Denmark, 1977-2012. Oral Oncol. 2015;51(11):982-984. https://doi.org/10.1016/j.oraloncology.2015. 08.006 .

6. Patel MA, Blackford AL, Rettig EM, Richmon JD, Eisele DW, Fakhry C. Rising population of survivors of oral squamous cell cancer in the United States. Cancer. 2016;122(9):1380-1387. https://doi.org/10.1002/cncr.29921.

7. Rettig EM, D'Souza G, Thompson CB, et al. Health-related quality of life before and after head and neck squamous cell carcinoma: analysis of the surveillance, epidemiology, and end results-Medicare health outcomes survey linkage. Cancer. 2016; 122(12):1861-1870. https://doi.org/10.1002/cncr.30005.

8. Manne S, Hudson SV, Baredes S, et al. Survivorship care experiences, information, and support needs of patients with oral and oropharyngeal cancer. Head Neck. 2016;38(S1):E1935E1946. https://doi.org/10.1002/hed.24351.

9. Ringash J, Bernstein LJ, Devins G, et al. Head and neck cancer survivorship_learning the needs, meeting the needs. Semin Radiat Oncol. 2018;28(1):64-74. https://doi.org/10.1016/j.semradonc.2017. 08.008 .

10. Balfe M, O'Brien K, Timmons A, et al. The unmet supportive care needs of long-term head and neck cancer caregivers in the 
extended survivorship period. J Clin Nurs. 2016;25(11-12) 1576-1586. https://doi.org/10.1111/jocn.13140.

11. Malloy KM, Pou AM. Survivorship. Otolaryngol Clin NA. 2017; 50(4):853-866. https://doi.org/10.1016/j.otc.2017.04.005.

12. Koch R, Wittekindt C, Altendorf-Hofmann A, Singer S, Guntinas-Lichius O. Employment pathways and workrelated issues in head and neck cancer survivors. Head Neck. 2014;37(4):585-593. https://doi.org/10.1002/hed.23640.

13. Kam D, Salib A, Gorgy G, et al. Incidence of suicide in patients with head and neck cancer. JAMA Otolaryngol Head Neck Surg. 2015;141(12):1075-1077. https://doi.org/10.1001/jamaoto.2015. 2480 .

14. Osazuwa-Peters N, Adjei Boakye E, Walker RJ, Varvares MA. Suicide: a major threat to head and neck cancer survivorship. J Clin Oncol. 2016;34(10):1151-1151. https://doi.org/10.1200/ JCO.2015.65.4673.

15. Lydiatt WM. Prevention of depression with escitalopram in patients undergoing treatment for head and neck cancer. JAMA Otolaryngol Head Neck Surg. 2013;139(7):678-686. https://doi.org/10.1001/jamaoto.2013.3371. Published online June 20, 2013.

16. Roman BR, Goldenberg D, Givi B, The Education Committee of American Head and Neck Society (AHNS). AHNS seriesDo you know your guidelines? Guideline recommended follow-up and surveillance of head and neck cancer survivors. Head Neck. 2016;38(2):168-174. https://doi.org/10.1002/hed. 24100.

17. Simcock R, Simo R. Follow-up and survivorship in head and neck cancer. Clin Oncol. 2016;28(7):451-458. https://doi.org/10. 1016/j.clon.2016.03.004.
18. Flynn CJ, Khaouam N, Gardner S, et al. The value of periodic follow-up in the detection of recurrences after radical treatment in locally advanced head and neck cancer. Clin Oncol. 2010;22(10):868-873. https://doi.org/10.1016/j.clon.2010.05.016.

19. Berkowitz C, Allen DH, Tenhover J, et al. Knowledge and preferences of primary care providers in delivering head and neck cancer survivorship care. J Cancer Educ. 2017;33:1-5. https:// doi.org/10.1007/s13187-017-1250-3.

20. Campbell BH, Massey BL, Myers KB. Survivorship care plans for patients with head and neck cancer. Arch Otolaryngol Head Neck Surg. 2012;138(12):1116-1119. https://doi.org/10.1001/jamaoto. 2013.683

21. Montero-Miranda PH, Ganly I. Survivorship-competing mortalities, morbidities, and second malignancies. Otolaryngol Clin North Am. 2013;46:1-30. https://doi.org/10.1016/j.otc.2013.04.008.

\section{SUPPORTING INFORMATION}

Additional supporting information may be found online in the Supporting Information section at the end of this article.

How to cite this article: Cognetti DM, Villaflor VM, Fakhry C, Miller MC, Malloy KM. Survivorship support in head and neck cancer: American Head and Neck Society survey. Head \& Neck. 2020;42:939-944. https://doi.org/10.1002/ hed.26066 